\title{
STUDY ON CARBON FOOTPRINT AND SPATIAL DISTRIBUTION CHARACTERISTICS OF HUMAN ACTIVITIES IN JIUZHAI VALLEY SCENIC AREA
}

\author{
SUN, R. H. ${ }^{1}-$ YE, X. L. ${ }^{1^{*}}-$ GAO, J. ${ }^{2}-$ ZHU, Z. F. ${ }^{3}-$ DU, J. ${ }^{3}$ \\ ${ }^{I}$ Department of Business Administration, School of Management, Shanghai University of \\ Engineering Science, 333 Longteng Road, Songjiang District, Shanghai, China \\ (e-mail: sunruihong@sues.edu.cn; phonelfax: +86-21-6787-4142) \\ ${ }^{2}$ School of Tourism, Shanghai Normal University, \\ 100 Guilin Road, Xuhui District, Shanghai, China \\ (e-mail: gaojun@shnu.edu.cn; phonelfax: +86-21-6432-2447) \\ ${ }^{3}$ Jiuzhai Valley Scenic Area Administration, Zhangzha Town, Jiuzhaigou County, Aba Tibetan \\ and Qiang Autonomous Prefecture, Sichuan Province, China \\ (e-mail:183796414@qq.com; phonelfax:+86-83-7773-9753) \\ *Corresponding author \\ e-mail: yexinliang@sues.edu.cn \\ (Received $27^{\text {th }}$ Feb 2019; accepted $3^{\text {rd }}$ May 2019)
}

\begin{abstract}
As a nature reserve with extremely vulnerable ecological system, Jiuzhai Valley must strike a balance between climate change, tourism growth and environmental protection in the future development. Carbon footprint is a key tool to measure the environmental impact of human activities. The key factors of carbon emission reduction in Jiuzhai Valley Nature Reserve can be found through carbon footprint evaluation and targeted carbon emission reduction measures can be put forward. In this paper, the carbon emission inventory based on mixed life cycle is introduced to calculate the carbon emissions within the boundary of Jiuzhai Valley Nature Reserve, evaluate its carbon footprint and find out its spatial distribution pattern in order to find out the key factors and links in the improvement of the low-carbon management in Jiuzhai Valley. The study found that the commercial activities of operating companies providing services to tourists (such as transportation and catering) are a major part of carbon emissions, followed by tourist tours and the management and maintenance activities of the Authority, the residential carbon emissions which come from the village daily life and private car driving. The low carbon emission reduction in Jiuzhai Valley should focus on the optimization of land use, the control of the number of residents and tourists, and the sharing of responsibility for emission reduction.
\end{abstract}

Keywords: carbon emission, carbon footprint, spatial distribution, human activities, Jiuzhai Valley scenic area

\section{Introduction}

Jiuzhai Valley Nature Reserve was established in 1978, and was approved to establish national scenic area in 1984. In 1992, UNESCO designated Jiuzhai Valley as "World Natural Heritage", and then Jiuzhai Valley joined the World Network of Man and Biosphere Reserves. Jiuzhai Valley Nature Reserve is located on the eastern edge of the Qinghai-Tibet Plateau. In general, it belongs to the alpine and gorge region landform。 The unique geological, geomorphological and natural geography conditions have created the alpine karst landscape and lake canyon scenery with large scale and unique shape. The ecological environment of Jiuzhai Valley is very fragile and sensitive, belonging to the "environmentally and cultural vulnerable areas" (Zhang and Zhu, 2007). In theory, Jiuzhai Valley should rely on ecotourism to protect the World Natural Heritage through 
small scale tourism that strictly limits the number of tourists according to the environmental capacity. However, this concept is challenged by mass tourism, aboriginal people getting rich from poverty and local economic growth in practice. Therefore, Jiuzhai Valley's scenic area management needs to consider a variety of demands to promote operational strategies.

This paper selects Jiuzhai Valley to carry out carbon footprint research based on the following considerations: first of all, tourism has become the economic artery of Jiuzhai Valley, and Jiuzhai Valley scenic area has become the local pillar industry and economic artery. Since its development in 1980, Jiuzhai Valley has experienced an average annual increase of $27 \%$. In 2012, the number of tourists has reached $3,638,618$, and tourism income has accounted for more than $90 \%$ of the local economic income. Tourism has effectively promoted local economic development and the employment of residents out of poverty. Secondly, tourism growth poses a severe challenge to the ecological carrying capacity of scenic spot, which are often overloaded. According to Zhang Xiaoping, former director general of Jiuzhai Valley Administration, and related scholars, the daily tourist psychological capacity of Jiuzhai Valley scenic area is 12000 people (with different values in different seasons), the best (most appropriate) daily capacity is 18000 people, and the comprehensive environmental capacity is 22000 people, the maximum daily capacity can reach 28000 people, and the annual capacity is 2.6 million to 4.38 million people (Zhang and Zhu, 2007). According to the tourism scale of Jiuzhai Valley in 2016, the number of tourists was already at the carrying capacity boundary and breaking the limiting value. Thirdly, Jiuzhai Valley Administration ecological protection work has been carried out in an orderly manner and the data has been sorted out and improved. The Academic Research Office and Protection Department of Jiuzhai Valley Administration has carried out a general survey and quantitative statistics on the species of animals and plants inside the reserve area, and has more detailed records and observation data on the land use change of Jiuzhai Valley. The Protection Department is responsible for the disposal of waste and feces and sewage in the scenic area of Jiuzhai Valley, which can obtain basic information through interviews. The Jiuzhai Valley Administration has a Resident Management Office, which is responsible for the management of residents in the scenic area, has relatively complete information on residents' living conditions, income changes, vehicle ownership situation and so on.

This paper applies the theory of carbon footprint to Jiuzhai Valley Nature Reserve and discusses how to reduce carbon footprint and implement carbon management to balance ecological vulnerability protection and tourism economic growth. This paper combines the international common carbon footprint inventory to construct the evaluation model of tourism carbon footprint suitable for minority areas, and verifies it through the field interview data of Jiuzhai Valley, introduces stakeholders to distinguish the responsibilities of Jiuzhai Valley tourism industry in reducing emissions according to the results of carbon footprint evaluation, and provides theoretical and empirical support for putting forward and perfecting low-carbon construction and sustainable development of Jiuzhai Valley tourism industry.

\section{Research object and scheme design}

\section{The basic situation of Jiuzhai Valley scenic area}

Tourism activities are mainly carried out in the experimental area of Jiuzhai Valley scenic area, accounting for $8.53 \%$ of the total area of nature reserve. The changes in 
population and land use in Jiuzhai Valley are closely related to its history of development. Figure 1 shows the changes of tourists and population in Jiuzhai Valley from 1978 to 2012. The number of tourists fluctuated greatly during that period. The two biggest fluctuations occurred in the early stages of tourism development in Jiuzhai Valley in 1980 with a sharp increase of tourists and the rapid development of tourism after 1989, followed by three small fluctuations, which are respectively after the 1997 financial crisis, after SARS in 2003 and after Sichuan earthquake in 2008. In contrast, the number of residents has maintained a steady and slow growth, its population growth rate showed a downward trend.

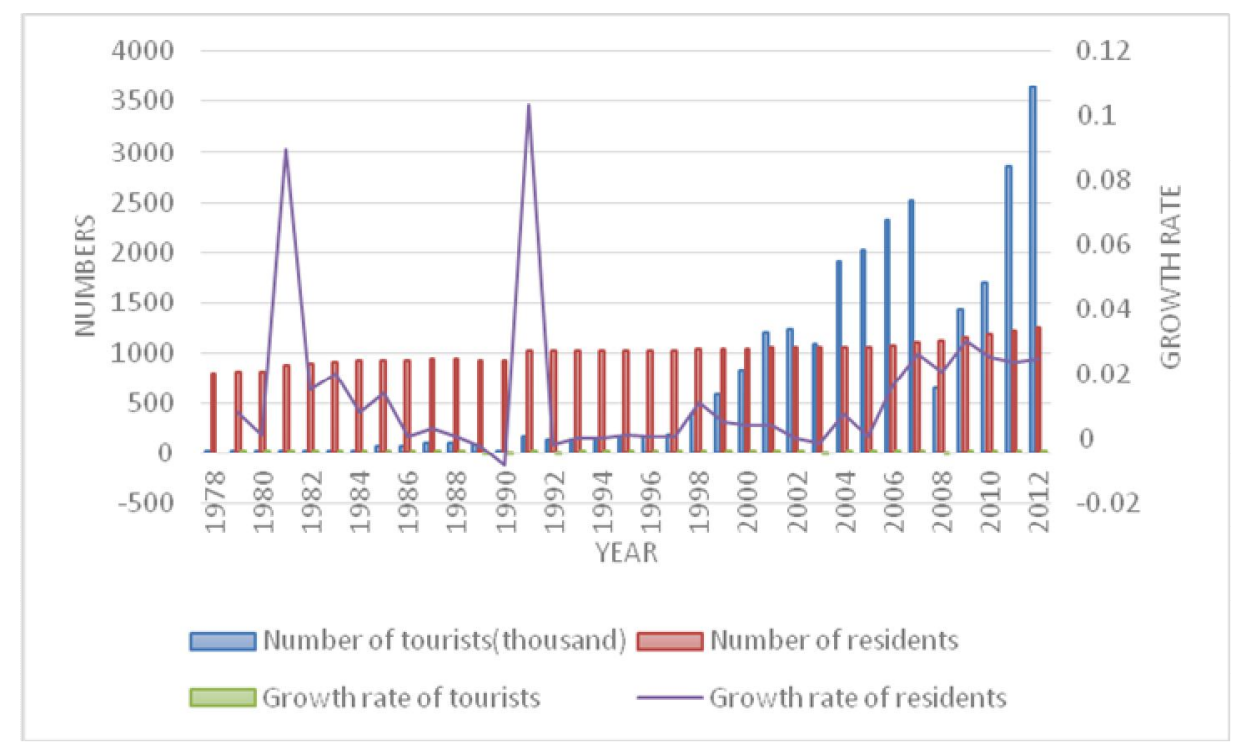

Figure 1. Changes in the number of tourists and residents in Jiuzhai Valley

Human activities in different periods have a great influence on the landscape pattern and land use of Jiuzhai Valley Nature Reserve. Figure 2 reflects the land use changes in Jiuzhai Valley Nature Reserve in four periods from 1975 to 2012. The reasons of the land use change of each period can be found in the development decision and course of the specific period at that time.

Before 1978, Jiuzhai Valley production method and life style were mainly agricultural grazing and forestry felling. The local people made a living by logging, farming, grazing, hunting and digging medicine and lived a life of half farming and half grazing. In 1966, the original Bailong River Forestry Bureau began opening work circle to felling timber in Jiuzhai Valley. Jiuzhai Valley Nature Reserve was established in 1978, but forest logging was not completely banned because of sectoral economic interest until 1992 when it was listed as the World Natural Heritage. In 1984, the national scenic spot was established, and Jiuzhai Valley officially opened to the outside world. Tourism started and the construction of tourist facilities was started. Since 1987, especially in 1990, Jiuzhai Valley tourism has entered a period of rapid growth-the number of tourists had increased exponentially and the tourism economy had grown rapidly. However, due to extensive management, the phenomenon of urbanization and over-commercialization gradually appeared in the reserve, which caused certain damage to the ecological environment (Zhou, 1998). Since 1999, Jiuzhai Valley has taken strict and scientific measures to protect the environment. On the one hand, the traditional 
living habits of residents have been changed, and natural gas cooking has been realized. In 2000, the hotels in the reserve was dismantled comprehensively, and implement the policy of returning the grain plots to forestry. From 2008 till now, Jiuzhai Valley has been hit hard by the earthquake and the tourists have plummeted, and the water area and mountain body within the territory have been significantly destroyed by earthquake and debris flow. Post-disaster reconstruction of the scenic area and tourism industry recovery has become the main theme. From the perspective of land use changes in Jiuzhai Valley, such events as stopping forest harvesting, developing tourism, returning the grain plots to forestry, demolishing hotels and other operational sites in scenic spots, and rebuilding after the earthquake have played a very important role in restoring and increasing the forest land of Jiuzhai Valley, changing the way of residents life by returning grain plots to forestry to engage in tourism, reducing a large amount of constructive land and standardizing the land management of Jiuzhai Valley.

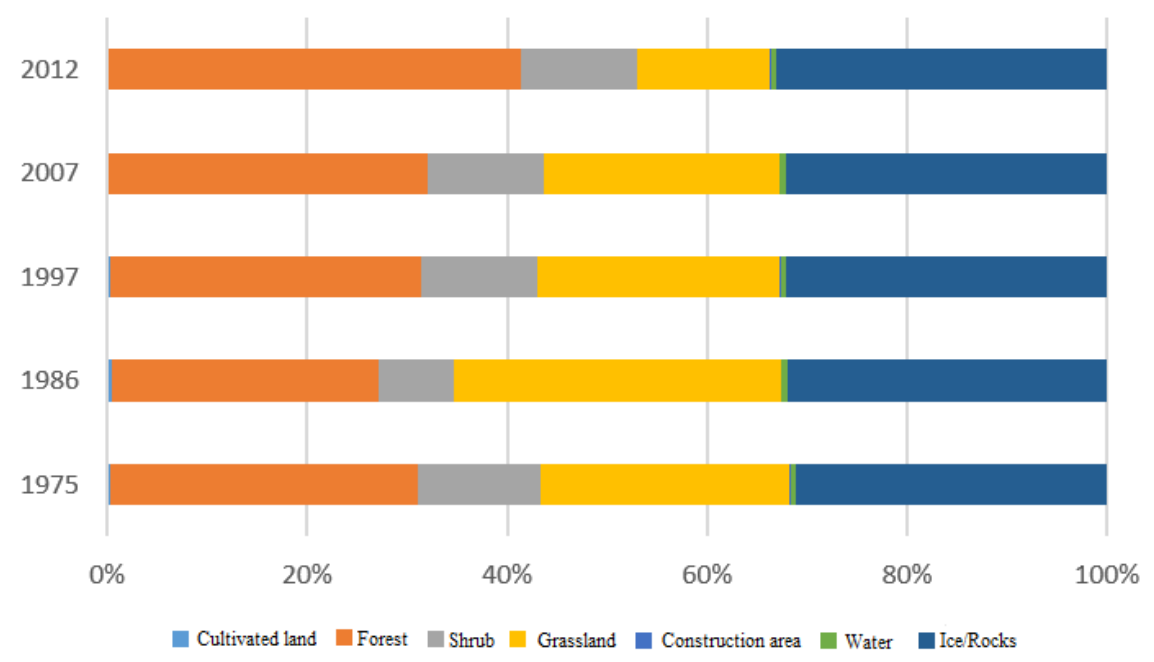

Figure 2. Percentage change of different land use types in Jiuzhai Valley

\section{Review of carbon footprint research}

From the perspective of source and nature, carbon footprint is a spatial concept, which is measured in the unit of area. Kitzes and other scholars (Kitzes et al., 2009, 2007) regard carbon footprint as part of the ecological footprint, known as the "fossil energy footprint" or "carbon dioxide land", which is measured in gha (gha, the abbreviation of global hectare, one unit global hectare refers to a productivity space of 1 ha with an average global yield, the unit is $\mathrm{hm}^{2}$ ). There are also many scholars who tend to express carbon footprint in terms of carbon dioxide emissions or carbon dioxide equivalents, typical of which is that Wiedmann and Minx (2007) and Hertwich and Peters (2009) define carbon footprint as the total amount of carbon dioxide and other greenhouse gases emitted by a product's supply chain or life-cycle. Although the carbon footprint originated from the ecological footprint, it has formed its unique meaning on the basis of its "ecological footprint of carbon emissions" in practice, which becomes a token of greenhouse gas emissions taking into account global warming potential (GWP). Whether the area or the quality of measurement units are inadequate. Converting greenhouse gas emissions into land area requires a series of assumptions that increase the error and uncertainty of carbon footprint accounting (Lenzen, 2006). 
On the other hand, it is not accurate to express the carbon footprint by the quality of greenhouse gas, because carbon footprint is a spatial concept, and it is easy to lead misunderstanding if taking mass as the unit (Hertwich and Peters, 2009).

In order to distinguish the concept of carbon footprint and carbon emission, this paper adopts the definition of "productive land area needed to absorb carbon dioxide emissions from human activities". Carbon emissions are defined as "the direct or indirect carbon dioxide emissions in the entire life cycle or within a certain geographical range of an activity, a product (or service)".

Carbon footprint inventory of carbon emission sources is the first step in carbon footprint evaluation. Although greenhouse gas accounting standard is commonly used in footprint calculations, there is no mandatory carbon footprint verification (Pandey et al., 2011). The domestic and international studies on carbon emissions in specific regions based on greenhouse gas emission inventories mainly focus on the research of regional carbon emissions on the large and mesoscale scale, with the largest number of studies on the assessment of carbon footprint between countries and continents on a large scale. In view of the pressure of greenhouse gas emission reduction on countries brought by global climate change, different scholars put forward some practical amendments to the IPCC and other emission inventories and carry out the design and statistics of carbon emission inventory according to the characteristics of their respective countries and regions characteristics. Some scholars also put forward their views on the design and method of greenhouse gas emission inventory (Ravindranath and Ostwald, 2008). Ramaswami et al. (2008) developed a demand-oriented hybrid life-cycle approach that focuses on demand-oriented mixed greenhouse gas inventory method including urban direct greenhouse gas emissions related to final energy use, and indirect greenhouse gas emissions related to the main substances supporting the city. After that, some scholars have improved and applied the city inventory method based on the mixed life cycle inventory method (Kennedy et al., 2010, 2011).

\section{Evaluation and design of carbon footprint in Jiuzhai Valley}

Tourism is the only economic industry in Jiuzhai Valley. The type of economic activity in Jiuzhai Valley is tourism industry. All the main bodies in Jiuzhai Valley can be divided into tourists and organizations and individuals who provide services for tourists. Tourist activities in the scenic area impact on the environment is waste and sewage, feces. Organizations and individuals providing services to tourists include: residents, the commercial sector of the scenic area and the administration in Jiuzhai Valley. Jiuzhai Valley residents basically turn to tourism employment, their working carbon emissions can basically be included in the tourism industry carbon emissions, so the resident carbon emissions in Jiuzhai Valley come from the daily life and transportation of residents. The scenic area commerce provides the service of catering, shopping, transportation and sightseeing for tourists. Its environmental impact includes: fuel and electricity consumption, waste gas and waste water produced by business activities and so on. Administration carbon emissions are reflected in the daily office energy use, construction waste and vehicle use for construction and maintenance of scenic area, and the use of working vehicles for safety management and protection in scenic area.

According to the types of human activities in Jiuzhai Valley scenic area, there are mainly four kinds of activities: the first is the daily life of the residents in the reserve and the activities of participating in tourism management. The second is the tourism 
activities of tourists. The third is the commercial operation activities in the scenic area, involving the business activities of the three companies under the jurisdiction of the Jiuzhai Valley Administration, such as the joint venture company (operating the Nourilang Center), the tourist products company (operating the Shopping Center, VIP building and Heye Guesthouse), and sightseeing company (operating tourist vehicles). The fourth kind is the management and maintenance activities of the scenic area, including the construction and repair of the scenic area, the daily office work of the Administration Bureau, the safety protection and management of the scenic spot of the Administration, etc. Figure 3 lists the various departments involved in the statistics of the carbon emission inventory, among which, the Administration Bureau belongs to scenic area management department, the tourism company, the product company, and the jointly venture company are the scenic area commercial operation company.

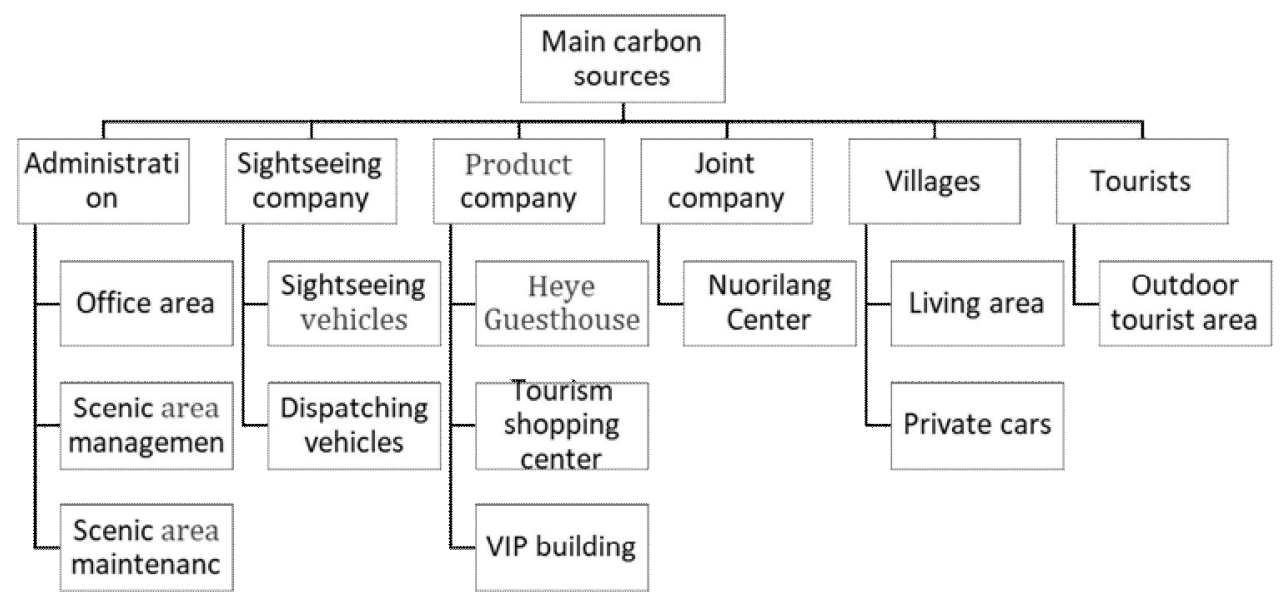

Figure 3. The main bodies involved in the Jiuzhai Valley carbon inventory

The inventory of carbon emissions based on mixed life cycle includes not only direct carbon emissions from energy activities but also indirect carbon emissions from power consumption and indirect carbon emissions from waste disposal. Direct carbon emissions of Jiuzhai Valley mainly come from energy activities, such as fuel consumption of traffic vehicles, use of natural gas, energy consumption of Nourilang diesel stove and charcoal heating in winter of residents in the scenic area. Electricity belongs to indirect carbon emissions. The feces, garbage, sewage are also considered as indirect carbon emission because all of them are transported out of Jiuzhai Valley for treatment and its carbon emissions occur outside the scenic area. The projects in Jiuzhai Valley that can be included in carbon inventory statistics are as follows, as shown in Figure 4.

Greenhouse gas emissions need to focus not only on direct emissions inside the nature reserve, but also on indirect emissions from energy consumption and waste disposal. Compared with the IPCC inventory classification statistics, Jiuzhai Valley's greenhouse gas accounting is clear and simple, because Jiuzhai Valley's economic activity type is only tourism industry. All the main bodies in Jiuzhai Valley can be divided into tourists and organizations and individuals that provide services for tourists. Tourist activities in the scenic area impact on the environment is waste and sewage, feces. Organizations and individuals providing services to tourists include: residents, the commercial sector of the scenic area and the administration in Jiuzhai Valley. Jiuzhai 
Valley residents basically turn to tourism employment, their working carbon emissions can basically be included in the tourism industry carbon emissions, so the resident carbon emissions in Jiuzhai Valley come from the daily life and transportation of residents. The scenic area commerce provides the service of catering, shopping, transportation and sightseeing for tourists. Its environmental impact includes: fuel and electricity consumption, waste gas and waste water produced by business activities and so on. Administration carbon emissions are reflected in the daily office energy use, construction waste and vehicle use for construction and maintenance of scenic area, and the use of working vehicles for safety management and protection in scenic area.

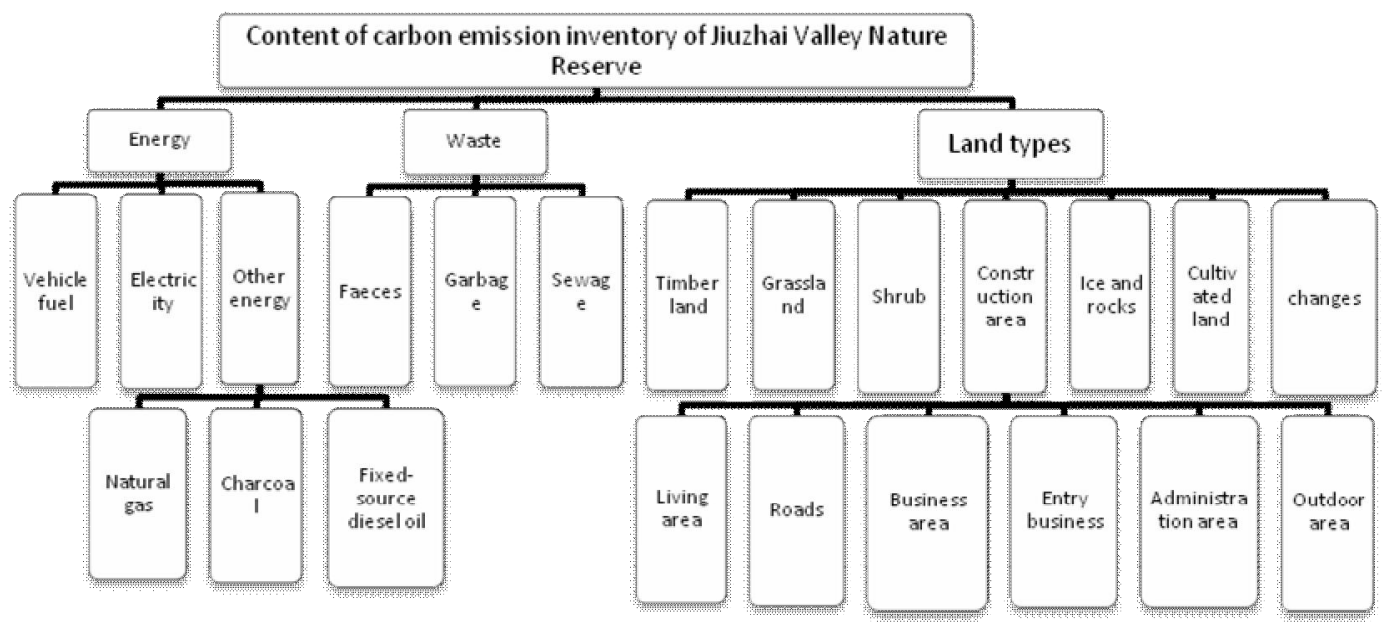

Figure 4. Statistics on carbon emission inventory in Jiuzhai Valley

There are three sources of carbon emissions in Jiuzhai Valley: energy, waste, and land use. Among them, construction land and cultivated land in land use are sources of carbon emissions. But since 2003-2004, the cultivated land in Jiuzhai Valley has been converted into forestry, and the carbon source of cultivated land has not existed. Carbon emissions from construction land are energy consumption and waste emissions from that region, so there is no need for double counting. The other land types of Jiuzhai Valley play a role of carbon sink and have the function of carbon storage and carbon absorption except for construction land. According to the carbon emission inventory, the activities data level of the carbon source in Jiuzhai Valley is counted, and the emission coefficient method is used to calculate the carbon emissions of each carbon source in Jiuzhai Valley. NPP carbon sink method can be adopted in the evaluation of carbon footprint and carbon balance. Figure 5 shows the process of carbon footprint evaluation in Jiuzhai Valley Nature Reserve.

\section{Evaluation methods and data acquisition}

\section{Evaluation methods}

\section{The evaluation of carbon emission and the selection of emission coefficient}

The calculation of carbon emissions from energy and waste refers to the calculation method recommended by IPCC2006 Greenhouse Gas Emission Inventory Guidelines, which is also adopted and used for reference by international general inventory 
guidelines such as PAS2050, ISO14064. Energy carbon emission calculation is relatively simple, the key of which is to determine the corresponding energy carbon emission coefficient. As for the units of measurement, carbon emissions, carbon storage, and carbon absorption all use kilograms or tons $(\mathrm{kg}$ or $\mathrm{t})$, the unit of land area and carbon footprint is hectares $\left(\mathrm{hm}^{2}\right)$, and the units of other indexes in this paper all refer to the national standard GB 3101-1993 General Principles of Quantities, Units and Symbols.

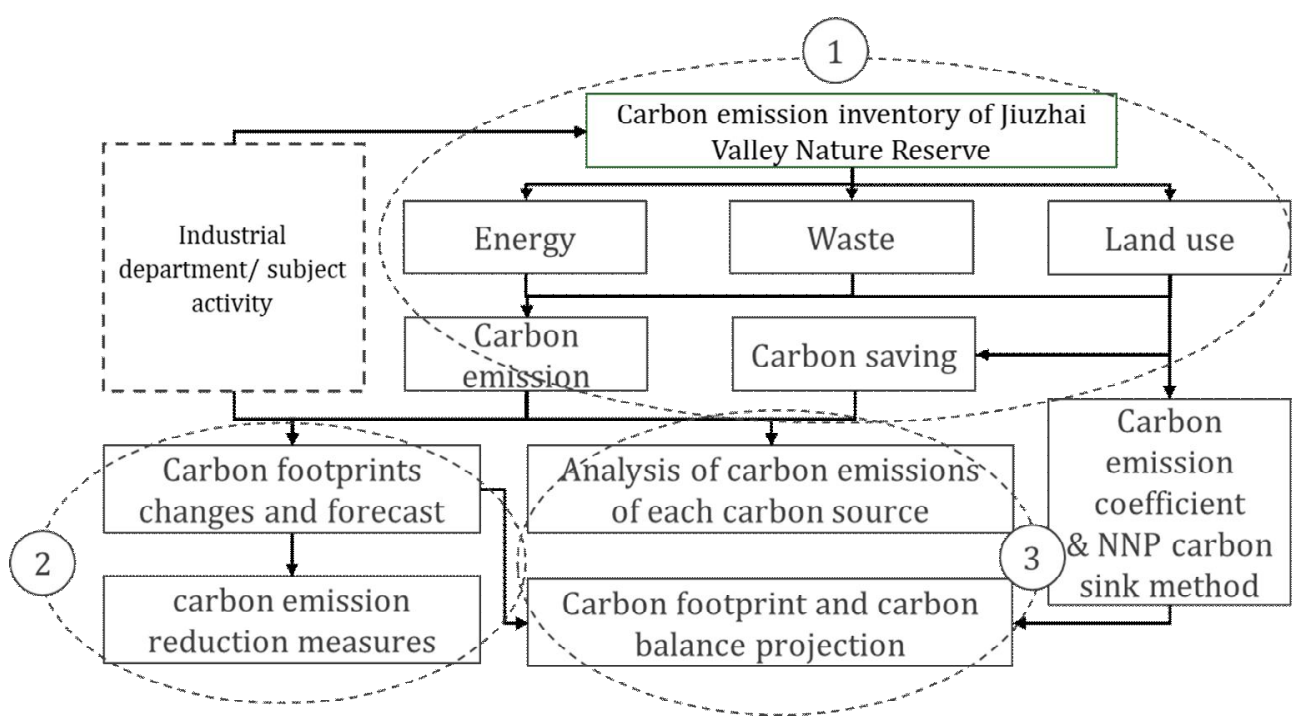

Figure 5. Evaluation design of carbon footprint in Jiuzhai Valley

\section{Carbon footprint calculation}

This paper adopts the net primary productivity (NPP) index to reflect the carbon absorption of different vegetation, and calculate the area of productive land needed to absorb carbon emissions, that is, carbon footprint. The NPP of forests, grasslands, thinly forested shrubs and water bodies refer to the studies of different domestic scholars (Du et al., 2010; Gu et al., 2007; Liu et al., 2010), while the NPP of bare rock refers to Lu et al. (2005) study on Sichuan in the western region, which makes a detailed analysis of the calculation in the paper.

\section{Calculation of carbon balance in Jiuzhai Valley}

This paper analyzes the carbon balance of Jiuzhai Valley reserve ecosystem from two aspects. One is the comparison between carbon emission from human activities and carbon storage and carbon absorption in Jiuzhai Valley. The other is the comparison between the human activities carbon footprint and Jiuzhai Valley productive land area. The former analysis is based on the carbon emission inventory. According to the national carbon emission inventory, the types and quantities of carbon emission sources and absorption sinks in Jiuzhai Valley Nature Reserve are listed in the form of incoming and outgoings, which is convenient to observe the situation of carbon balance. The latter one refers to the analysis based on ecological carbon balance index. If the ecological carbon balance index is greater than 1 , it means that there is ecological deficit. If the ecological carbon balance index is equal to 1 , it shows that ecology is in the critical 
state of carbon balance. If the ecological carbon balance index is less than 1 , it indicates that there is ecological surplus. The smaller the ecological carbon balance index, the more intact the ecosystem is and is less disturbed by human activities.

\section{Data acquisition}

\section{The interview with various department in Jiuzhai Valley}

In December 2012, the author conducted a half-month departmental interview in Jiuzhai Valley Nature Reserve, covering 16 departments, the departments and interview content are as shown in Table 1.

Table 1. Interview department and content of Jiuzhai Valley administration

\begin{tabular}{|c|c|}
\hline Interview department & Interview content \\
\hline HR Office & $\begin{array}{l}\text { For the division and arrangement of responsibilities of the Jiuzhai Valley } \\
\text { Administration, final report of the Administration over the years }\end{array}$ \\
\hline Marketing Department & $\begin{array}{l}\text { Get the number of tourists, the origin and composition of tourists, the } \\
\text { consumption of tourists and sample survey conditions }\end{array}$ \\
\hline Information Center & For its management of tourist ticketing and the tracing of tourists \\
\hline Office of Academic Research & $\begin{array}{c}\begin{array}{c}\text { Protection of vegetation, types and changes of land use, boundary of } \\
\text { reserve }\end{array} \\
\end{array}$ \\
\hline Resident Management Office & $\begin{array}{l}\text { The number of residents, the number of households in village, the building } \\
\text { area of village, the conversion of farmland to forests, etc. }\end{array}$ \\
\hline Security Department & $\begin{array}{c}\text { Reserve waste disposal, fecal disposal, sewage treatment, resident charcoal } \\
\text { procurement }\end{array}$ \\
\hline Legal Department & Number and type of private cars owned by the residents \\
\hline Supervision Department & Monitoring the energy consumption of each department \\
\hline Construction Department & Construction of scenic area, construction waste and use of vehicles \\
\hline $\begin{array}{l}\text { Administration Office and Drivers } \\
\text { Office }\end{array}$ & $\begin{array}{l}\text { Number of vehicles, types of vehicles, usage condition in the Valley, } \\
\text { mileage and fuel consumption owned by the Administration }\end{array}$ \\
\hline Sightseeing Company & $\begin{array}{l}\text { Vehicle types and quantity changes, fuel consumption and usage, vehicle } \\
\text { scheduling management }\end{array}$ \\
\hline Product Company & $\begin{array}{l}\text { Energy consumption of the commerce in the Valley such as catering, } \\
\text { accommodation, shopping, number of visitors and consumption }\end{array}$ \\
\hline Joint Venture Company & Telephone interviews to learn about vehicles, energy use \\
\hline Tourist Center & Jiuzhai Valley scientific research achievements presentation, tourist survey \\
\hline Finance Department & Involving confidential not being interviewed \\
\hline Stockaded Village & $\begin{array}{c}\text { Go to the village committee and residents' home of Heye Village, Zharu } \\
\text { Village, and Shuzheng Village to interview and observe }\end{array}$ \\
\hline Postdoctoral Research Station & Understanding the construction of low carbon scenic area \\
\hline
\end{tabular}

\section{Public data acquisition}

Statistical yearbook

China Energy Statistics Yearbook 2011, Sichuan Energy Statistics Yearbook, National Statistical Yearbook, Tourism Statistics Yearbook.

Google data base

The data of total carbon emissions, per capita carbon emission, electricity production, power carbon emission both at home and abroad, population size and population growth rate of China are selected from World Bank to analyze in this paper. 
Authoritative report

IPCC 2006 Inventory Guideline, 2011 Datum Line Emission Factor of China Regional Power Grid released by the Climate Department of the State Development and Reform Commission.

\section{Other data acquisition}

Survey data on vegetation and water bodies in Jiuzhai Valley

Referring to Liu and Zhang (2007) Biodiversity of Jiuzhai Valley Nature Reserve.

Data on land use types and changes in Jiuzhai Valley from 1975 to 2007

Referring to Deng (2011) Landscape Change and Protection in Jiuzhai Valley Nature Reserve, The Influence of Tourism Development on Landscape Pattern Change of Jiuzhai Valley Nature Reserve, and the doctoral thesis of Research on the Causes and Protection of Tourism Landscape of Jiuzhai Valley World Heritage Site.

The data of land use changes in 1997, 2007, 2012

Remote sensing images from the Chinese resource satellite remote sensing processor.

\section{Research results and analysis}

According to the carbon emission sources of Jiuzhai Valley scenic area, the carbon emissions from energy, waste and different land use are calculated respectively. The results show that the total carbon emissions of human activities in Jiuzhai Valley in 2012 was 21118.41 tons. From the emission source of the carbon footprint of human activities, the carbon footprint generated by energy consumption accounted for $81.86 \%$ of the total carbon footprint, while the carbon footprint of waste accounted for $18.14 \%$. In the energy carbon footprint, the carbon footprint of traffic vehicles using moving source fuel accounted for $54.84 \%$, in which, the size of the carbon footprint was followed by tourists sightseeing transportation, private cars of residents and working vehicles. The carbon footprint of electric power accounted for $35.62 \%$, the other energy consumption produces the smallest carbon footprint, and the size of carbon footprint of which was followed by gas, charcoal and fixed-source diesel.

According to the conversion formula of carbon emission and ecological footprint, the carbon footprint of human activities in Jiuzhai Valley can be calculated to be $3872.9 \mathrm{hm}^{2}$ in 2012, accounting for $5.94 \%$ of the biological productivity area (excluding construction land) in Jiuzhai Valley Nature Reserve. In terms of ecological footprint, carbon emissions from human activities in Jiuzhai Valley have very little impact on the environment of the reserve, far from reaching the upper limit of ecological carrying capacity in Jiuzhai Valley Nature Reserve. Jiuzhai Valley Nature Reserve still has $94.06 \%$ of the land to provide China with carbon sinks while supporting the development of tourism and the life of the residents at the same time.

\section{Carbon footprint analysis of different subjects}

From the subjects of human activity carbon footprint, the operating company that provides tourists with transportation, catering, accommodation (guesthouse), shopping company has the largest carbon footprint, accounting for $56.78 \%$ of the total. Tourists' carbon footprint due to toilet use, water use, abandonment of waste and other behavior 
in the process of sightseeing ranks second, accounting for $22.38 \%$ of the total. The carbon footprint of the residents in the reserve caused by family life, the family car, the family commerce and so on ranks the third, accounting for $11.12 \%$ of the total. The carbon footprint of Administration caused by the daily work, the construction and maintenance of protected area facilities and the management of protected areas accounts for $9.72 \%$ of the total.

From the point of view of the final allocation of carbon footprint, the management and maintenance of reserve by commerce and Administration are all carried out to meet the material and spiritual needs of the tourist during their tourism process, and their carbon footprint will eventually be transferred to the tourists. From this point of view, tourists eventually bear $88.88 \%$ of the carbon footprint and the rest are born by the residents. In 2012, the total number of tourists in Jiuzhai Valley was 3,638,618, and the total number of residents in Jiuzhai Valley was 1,241. The average carbon footprint per tourist was $0.00095 \mathrm{hm}^{2}$, while the carbon footprint per inhabitant was $0.347 \mathrm{hm}^{2}$.

\section{Per capita carbon footprint of tourists and residents}

As Table 2 shows, the carbon footprint per resident is 366.81 times the carbon footprint per tourist. In other words, the carbon footprint of 367 tourists is the same as that of one resident. Or one tourists come to Jiuzhai Valley Reserve 367 times can produce a carbon footprint equal to the carbon footprint of one resident. It is true that residents live in the Valley 365 days a year, and each tourist stays for only one day. However, if you compare the carbon footprint of 0.000951 per person per day to that of a tourist, the carbon footprint of the resident is still greater. It shows that the impact of individual resident on the ecological environment of Jiuzhai Valley is greater than that of individual tourist.

Table 2. Carbon footprint of tourists versus residents in 2012

\begin{tabular}{c|c|c|c|c|c|c}
\hline $\begin{array}{c}\text { Carbon footprint } \\
\text { allocation objects }\end{array}$ & $\begin{array}{c}\text { Carbon } \\
\text { emissions t }\end{array}$ & $\begin{array}{c}\text { Carbon } \\
\text { footprint } \mathbf{~ h m}^{\mathbf{2}}\end{array}$ & Percentage & $\begin{array}{c}\text { Number of } \\
\text { people in } \\
\mathbf{2 0 1 2}\end{array}$ & $\begin{array}{c}\text { Per capita } \\
\text { carbon } \\
\text { emissions t }\end{array}$ & $\begin{array}{c}\text { Per capita } \\
\text { carbon } \\
\text { footprint } \mathbf{h m}^{\mathbf{2}}\end{array}$ \\
\hline Reserve residents & 2348.26 & 430.65 & $11.78 \%$ & 1241 & 1.89 & 0.35 \\
Tourists & 18770.15 & 3442.26 & $88.22 \%$ & 3638618 & 0.01 & 0.00095 \\
Total & 21118.41 & 3872.90 & $100.00 \%$ & 3639859 & & \\
\hline
\end{tabular}

The carbon footprint of one resident is the same as that of 367 tourists in the Reserve. In 2012, for example, 1241 residents in the Reserve produced the same carbon footprint as 455212 tourists. If the number of tourists is less than 455212 , the activity of residents is the main cause of the negative impact of human activities on the environment of the Reserve, and tourist activity is the secondary motivation. This also explains why we have observed that residents have much greater impact on the environmental problems of many tourist destinations than tourists. Especially for the tourist destination which is in the early stage of tourism development or has few tourists due to the lack of fame, the carbon footprint of resident activities is the largest among all human activities. The reasons are as follows: firstly, it is due to the lack of effective management of resident activities. Secondly, the tourist facilities and services are not perfect, so that the tourist stay time and consumption are less. Thirdly, the management and operation of tourist 
destination is not mature, which makes the Reserve lack of attraction and appeal, and lack of lasting competitiveness. As a result, the number of tourists is small, the number of returned customers is also small, and the public praise is not high.

\section{Spatial distribution of carbon footprint in Jiuzhai Valley in 2012}

\section{Analysis of carbon footprint distribution and carbon emission sources}

In view of that there is NPP coefficient transformation relationship between carbon footprint and carbon emissions, and the carbon footprint can also be explained from the perspective of carbon emissions, this part uses Jiuzhai Valley carbon emissions to analyze.

The location of the carbon footprint is shown in Figure 6. The highway in the Reserve is the largest carbon footprint producing area, accounting for $44.89 \%$ of the total carbon footprint, which is mainly caused by the traffic carbon emissions of sightseeing vehicles, working vehicles and private cars. Jiuzhai Valley outdoor tourism area (excluding highway) is the second largest area of carbon footprint, accounting for $22.43 \%$ of all carbon footprint, which is mainly caused by waste and power consumption in the Reserve. The carbon footprint in the entrance of Jiuzhai Valley accounted for $20.62 \%$, which mainly comes from the work of the commerce and Administration in the entrance of Jiuzhai Valley. Village carbon footprint should not be ignored, accounting for $10.40 \%$, mainly from the lives of residents and a small number of family business activities. The carbon footprint of Nuorilang is the smallest, mainly because there are only $10 \%$ tourists eating here, and the office and shopping space is small, so the carbon emission is low, which is $1.67 \%$. If the entrance of Jiuzhai Valley Nature Reserve is taken as the boundary, the carbon footprint inside the gate of Jiuzhai Valley Nature Reserve is only $3073.924 \mathrm{hm}^{2}$, accounting for $79.38 \%$ of the total carbon footprint and $4.71 \%$ of the biological productivity area of Jiuzhai Valley Nature Reserve.

Combined with the area of the site generating carbon footprint, it can be found that there are differences in carbon emission intensity of different plots in Jiuzhai Valley construction land. The road is the highest, which is followed by the village, the entrance of the Valley, Nuorilang, and the tourist area.

\section{Analysis of carbon emission intensity in different regions}

From the analysis of Figure 7, Jiuzhai Valley entrance Administration office has the highest carbon emission intensity, followed by the business in the entrance, the scenic tourist areas, scenic roads, Shuzheng Village, Zharu Village, Heye Village and so on. The reason for the high carbon emissions in the office building in the entrance lies in the fact that the office building has concentrated most of the staff of the Jiuzhai Valley Administration, and as a scenic spot, the staff are all on duty without holidays in the peak season. The calculation of carbon intensity adopts the land area rather than building area, so the carbon emission intensity is high, but the total amount is not big. The commerce in the entrance is the second largest area of carbon emission intensity, because the tourist's limited tourist demand in Jiuzhai Valley is released outside the Valley, and the commercial location in the entrance is good so that the consumption of dining, shopping and accommodation is increasing, so the intensity of carbon emission is relatively high. Scenic tourist area is the third largest area of carbon emission, because the tourist solid waste, feces, sewage produced the most in this area. Scenic 
road carbon intensity is also large, mainly because the total amount of vehicle carbon emissions is large. In summary, it can be seen that the office of the Administration should design corresponding energy saving and emission reduction daily norms, promote the staff to participate in the construction of low-carbon scenic area. The green consumption standards can be implemented for the commerce in the entrance, and carbon reduction targets should be put forward to commercial organizations. For waste management, it should focus on the management of tourists' abandonment of garbage and the cultivation of water-saving awareness. The management of road carbon emissions can be achieved by improving vehicle emission standards and operational efficiency.

\section{Environmental externality analysis of carbon footprint}

From the regional transfer of final carbon emissions, $47.3 \%$ of the carbon emissions generated by human activities in Jiuzhai Valley Nature Reserve are transferred outside the Reserve, while $52.7 \%$ of which are still in the Reserve. The total carbon footprint generated by $52.7 \%$ carbon emissions is $2041.05 \mathrm{hm}^{2}$, which accounts for only $3.13 \%$ of the biological productivity areas in Jiuzhai Valley, as shown in Table 3.

Table 3. Environmental externalities analysis of carbon footprint in Jiuzhai Valley

\begin{tabular}{|c|c|c|c|c|}
\hline Externality & $\begin{array}{c}\text { Carbon } \\
\text { emission } t\end{array}$ & $\mathbf{N P P} / \mathbf{h m}^{2} \mathbf{a}$ & $\begin{array}{c}\text { Carbon footprint } \\
\left(\mathbf{h m}^{2}\right)\end{array}$ & Percentage \\
\hline Carbon emissions still in the reserve & 11129.56 & 5.45 & 2041.05 & $52.70 \%$ \\
\hline Carbon emissions moved out of reserve & 9988.85 & 5.45 & 1831.85 & $47.30 \%$ \\
\hline
\end{tabular}
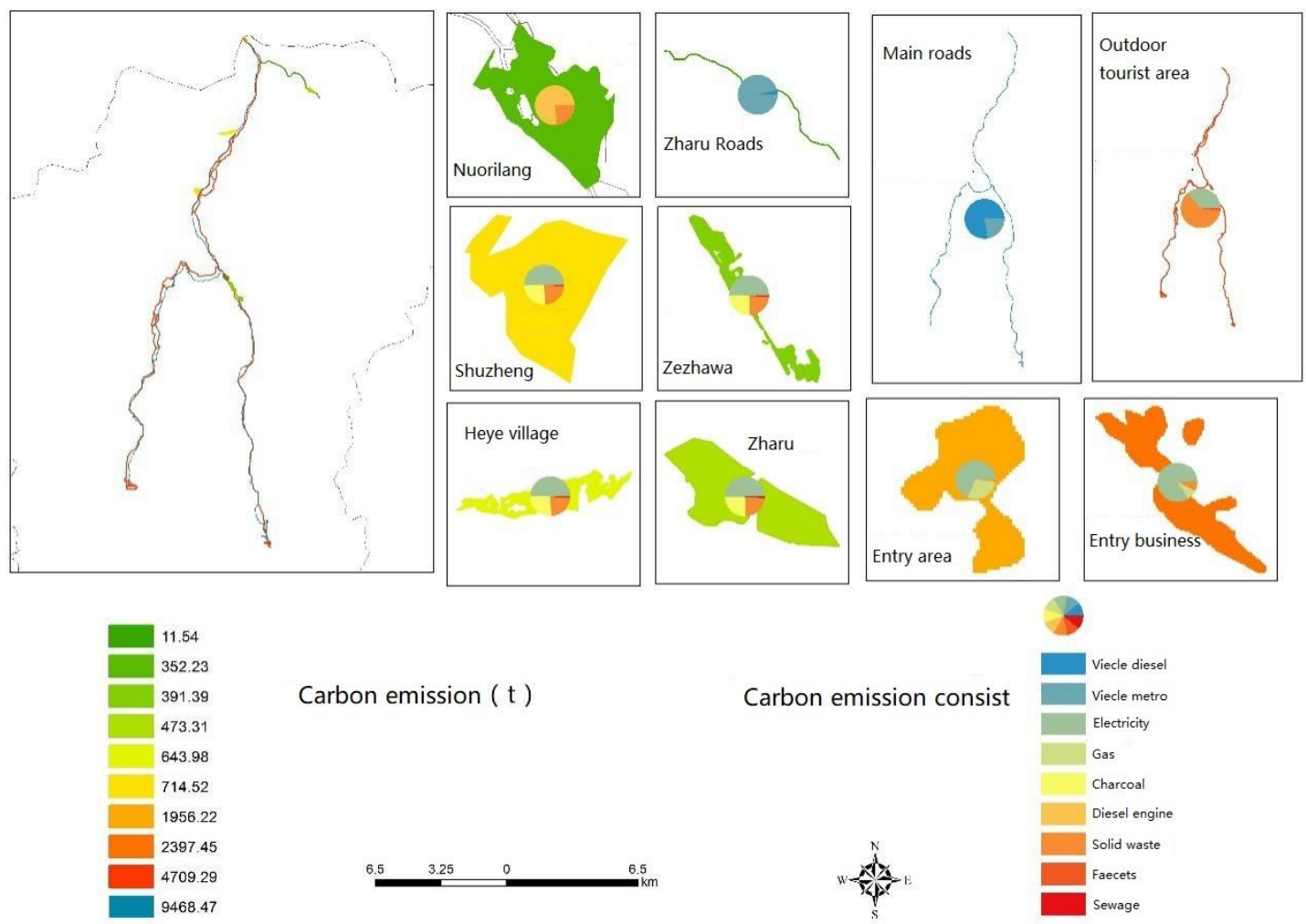

Figure 6. Regional analysis of carbon emissions in Jiuzhai Valley 

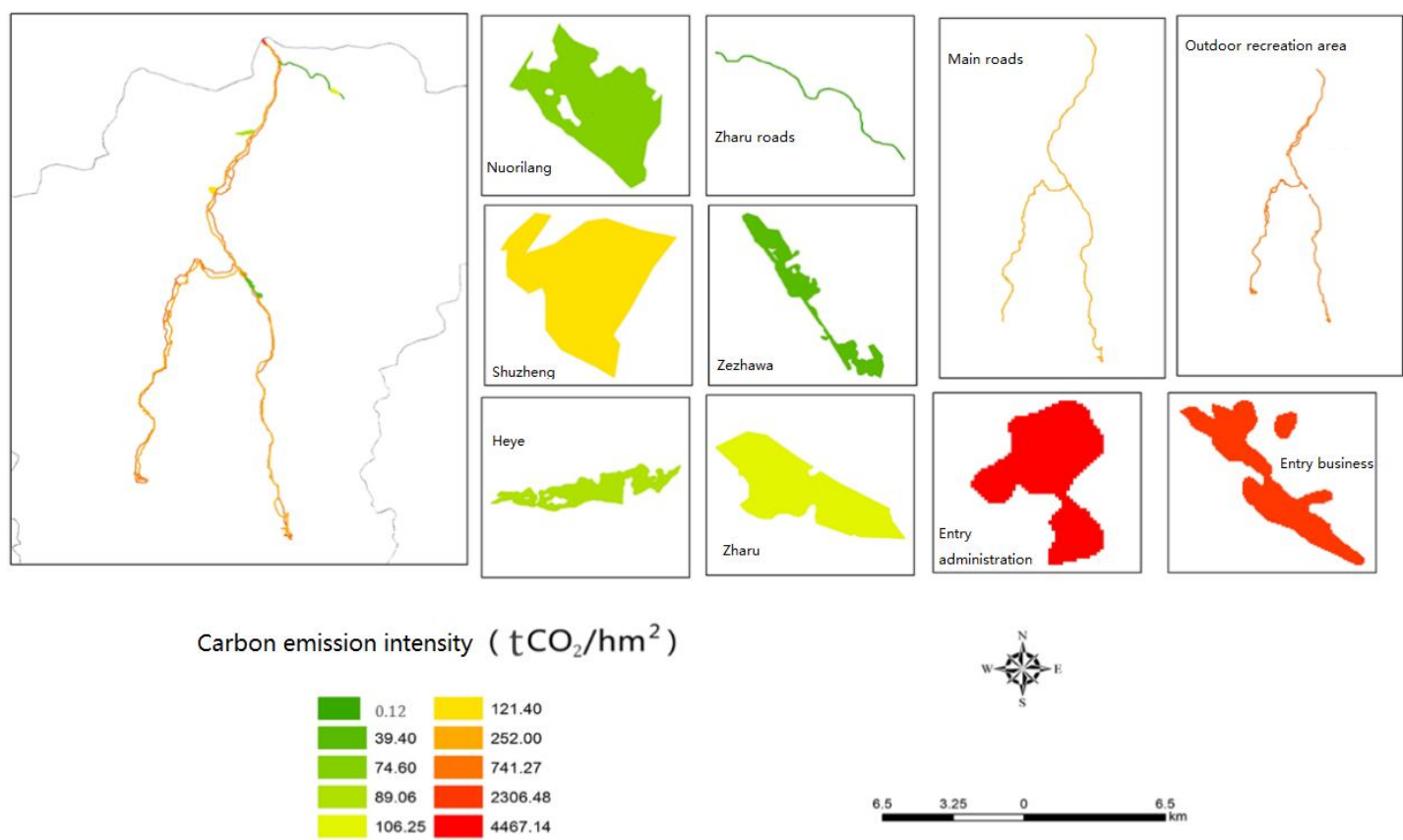

Figure 7. Carbon intensity analysis of different regions of Jiuzhai Valley construction land

The main reasons are as follows. First of all, the electric energy that used a lot in Jiuzhai Valley is the indirect carbon emission in the Reserve, and its actual carbon emissions occur in power plants and power stations. The carbon footprint generated by electricity use accounts for $29.16 \%$ of the total carbon footprint. Secondly, Jiuzhai Valley transfers all the waste treatment to the treatment plant outside the Valley. For example, the excrement is sent to Jiuzhai Valley fecal plant for decomposition, and sewage and refuse are transported to sewage treatment plant and refuse treatment plant, thus avoiding environmental pollution in the Reserve. The waste carbon footprint accounts for $18.14 \%$ of the total carbon footprint of Jiuzhai Valley.

The external transfer of carbon footprint in Jiuzhai Valley Nature Reserve reflects the transfer or shift of environmental costs, or environmental externalities, or the Not In My Back Yard (NIMBY) of the nature reserves. The fact that Jiuzhai Valley Nature Reserve transfers its carbon emissions to the external environment can contribute to the protection of its fragile ecosystem and diverse biological environment and to the increase of carbon storage and carbon absorption capacity of the vegetation in the protected areas, and the prevention of the conversion of soil to carbon emission. It is also beneficial to realize scale effect, save energy cost and improve energy utilization efficiency by unified treatment of waste outside the Valley.

\section{Conclusion and discussion}

In 2012, the carbon footprint of human activities in Jiuzhai Valley was $3872.9 \mathrm{hm}^{2}$, accounting for only $5.94 \%$ of the biological productivity area in Jiuzhai Valley Nature Reserve, and the average carbon emission per capita in Jiuzhai Valley was much lower than that in China and the world. This indicates that there is a huge ecological surplus 
between the total supply of productive land provided by the ecosystem of Jiuzhai Valley Nature Reserve and the carbon footprint generated by absorbing human activities, which can not only support the sustainable development of tourism in Jiuzhai Valley in the future, but also make a great contribution to our ecological environment, providing a large number of carbon sinks.

From the perspective of the main body of the carbon footprint, the final carbon footprint that tourists need to bear is $88.88 \%$ of the total carbon footprint, in which the direct carbon footprint generated by tourists' own activities accounts for only a third of the total carbon footprint, while the other two thirds of the total carbon footprint are transferred by the commerce and Reserve management. The operating company that provide tourists with transportation, catering, accommodation (guesthouse in the entrance), the shopping companies causes the largest carbon footprint, accounting for $44.78 \%$ of the total carbon footprint in Jiuzhai Valley.

Comparing the carbon footprint of tourists with that of residents, the carbon footprint produced by one resident in the Reserve is equivalent to that of 367 tourists. In 2012, for example, 1241 residents in the Reserve produced the same carbon footprint as 455212 tourists. If the number of tourists is less than 455212, the activity of residents is the main cause of the negative impact of human activities on the environment of the Reserve, and tourist activity is the secondary motivation.

From the perspective of the location of the carbon footprint, the Reserve road is the largest carbon footprint producing area, accounting for $44.89 \%$ of the total carbon footprint, which is caused by the traffic carbon emissions from tourist vehicles, working vehicles and private cars. Jiuzhai Valley outdoor tourism area (excluding highway) is the second largest area of carbon footprint, accounting for $22.43 \%$ of all carbon footprint, which is mainly caused by waste and power consumption in the Reserve. The carbon footprint in the entrance of Jiuzhai Valley accounted for $20.62 \%$, which mainly comes from the work of the commerce and Administration in the entrance of Jiuzhai Valley. Village carbon footprint should not be ignored, accounting for $10.40 \%$, mainly from the lives of residents and a small number of family business activities. The carbon footprint of Nuorilang is the smallest, accounting for $1.67 \%$.

From the regional transfer of final carbon emissions, $47.3 \%$ of the carbon emissions generated by human activities in Jiuzhai Valley Nature Reserve are transferred outside the Reserve, while $52.7 \%$ of which are still in the Reserve. The total carbon footprint generated by $52.7 \%$ carbon emissions is $2041.05 \mathrm{hm}^{2}$, which accounts for only $3.13 \%$ of the biological productivity areas in Jiuzhai Valley. The external transfer of carbon footprint in Jiuzhai Valley Nature Reserve reflects the transfer or shift of environmental costs, or environmental externalities, or the Not In My Back Yard (NIMBY) of the nature reserves.

From the perspective of the role of tourism development in carbon reduction, tourism development cannot reduce the carbon footprint of human activities in tourist areas, and tourism development is only conducive to the industrial transformation of tourist destinations, which may helps to avoid extensive industrial development producing a larger carbon footprint. Tourism development limits the unlimited growth of residents' carbon footprint, but increases the carbon footprint generated by tourists' tourism activities. Tourism activities become the main driving factor of the carbon footprint of nature reserves. If the environmental impact of nature reserve residents is greater than that of tourists, the reason is that the tourist destination is still in its early stage of 
development, or the tourism industry is not attractive enough to allow residents to move to tourism employment, and of course, the lack of supervision should be also to blame.

Acknowledgements. We are very grateful to Shangguan Xiaoyan in Jiuzhai Valley Administration Bureau, for helping data collection, thereby making our investigation proceeding smoothly; to Ye Bin for his unpublished energy consumption data; to director Deng Guiping for help at diverse aspects; to Zhan Qilin for technical help at various phases of the project. At last, but in the first place of course, we would like to express our special thanks to the grant of the National Social Science Foundation to the project study "Research on the development of domestic cruise tourism in China under the adjustment of supply structure" (No. 16BGL110), and the Ministry of Education to the youth planning project study "Research on the Environmental Externality and Green Governance Path of China's Cruise Industry from the Perspective of Ecological Economy" (No. 19YJC790117), and the National Science Foundation of China Funded Project: Investigation on the Pro-poor Tourism Effects and It's Influencing Mechanism on Settlement Space Evolution in Southwest Minority Villages (No.41661031).

\section{REFERENCES}

[1] Becken, S., Patterson, M. (2006): Measuring national carbon dioxide emissions from tourism as a key step towards achieving sustainable tourism. - Journal of Sustainable Tourism 14(4): 323-338.

[2] Chavez, A., Ramaswami, A. (2011): Progress toward low carbon cities: approaches for transboundary GHG emissions' footprinting. - Carbon 2(4): 471-482.

[3] Dong, Y., Yang, X. (2012): Review of low-carbon tourism research at home and abroad. - Journal of Southwest Agricultural University (Social Science Edition) 9(12): 5-11.

[4] Du, J., Shu, J., Zhang, L. (2010): The ecological footprint model based on net primary productivity and the comparative analysis with traditional model. - Ecology and Environmental Sciences 19(1): 191-196.

[5] Du, Q., Chen, Q., Lu, N. (2012): Forecast of China's carbon emissions based on modified IPAT model. - Journal of Environmental Science 32(9).

[6] Dubois, G., Ceron, J. P. (2006): Tourism/leisure greenhouse gas emissions forecasts for 2050: Factors for change in France. - Journal of Sustainable Tourism 14(2): 172-191.

[7] Fang, K., Dong, D., Lin, Z., Shen, W. (2012): Calculation method of energy ecological footprint based on global net primary productivity. - Acta Ecologica Sinica 32(9): 29002909.

[8] Geng, Y., Dong, H., Xi, F., Liu, Z. (2010): A review of the research on carbon footprint responding to climate change. - China Population Resources and Environment 20(010): 6-12.

[9] Gu, X., Huang, M., Ji, J., Wu, Z. (2007): The influence of climate change on vegetation net primary productivity in southwestern China during recent 20 years period. - Journal of Natural Resources 22(2).

[10] Han, L., Wu, J., Ren, R., Wang, Y. (2013): Researches on the structure trend of inbound tourism origin countries of China from 1995 to 2010. - Areal Research and Development 32(1).

[11] Hao, Y., Jiang, H., Wang, J., Jin, J., Ma, Y. (2009): Study on vegetation landscape change and habitat fragmentation in Jiuzhai Valley reserve. - Scientia Geographica Sinica 29(6): 886-892.

[12] Hertwich, E., Peters, G., Glen, P. (2009): Carbon footprint of nations: a global, tradelinked analysis. - Environmental science \& technology 43(16): 6414-6420.

[13] Kitzes, J., Peller, A., Goldfinger, S., Wackernagel, M. (2007): Current methods for calculating national ecological footprint accounts. - Science for Environment \& Sustainable Society 4(1): 1-9. 
[14] Kitzes, J., Galli, A., Bagliani, M., Barrett, J., Dige, G. et al. (2009): A research agenda for improving national Ecological Footprint accounts. - Ecological Economics 68(7): 19912007.

[15] Lenzen, M. (2006): Uncertainty in impact and externality assessments-implications for decision-making. - The International Journal of Life Cycle Assessment 11(3): 189-199.

[16] Lin, Z., Yin, P. (1994): Studies on the soil genetic characteristics and geographical distribution in Jiuzhai Valley region. - Journal of Southwest China Normal University (Natural Science) 19(001): 90-99.

[17] Liu, M., Li, W., Xie, G. (2010): Estimation of China ecological footprint production coefficient based on net primary productivity. - Chinese Journal of Ecology 29(3): 592597.

[18] Liu, S., Zhang, X. (2007): Biodiversity of Jiuzhai Valley Nature Reserve. - Sichuan Science and Technology Press, Chengdu.

[19] Lu, L., Li, X., Veroustraete, F. (2005): Terrestrial net primary productivity and its spatialtemporal variability in western China. - Acta Ecologica Sinica 25(5): 1026-1032.

[20] Pandey, D., Agrawal, M., Pandey, J. S. (2011): Carbon footprint: current methods of estimation. - Environmental Monitoring and Assessment 178(1-4): 135-160.

[21] Pandey, D. N. (2002): Global climate change and carbon management in multifunctional forests. - Current Science 83(5): 593-602.

[22] Pang, X., Bao, W. Jiang, Y., Wang, C. (2009): Comparison of soil physical properties under primary and secondary forests in Jiuzhai Valley and Huanglong Nature Reserves, Sichuan, China. - Chinese Journal of Applied \& Environmental Biology 6: 768-773.

[23] Ramaswami, A., Hillman, T., Janson, B., Reiner, M., Thomas, G. (2008): A demandcentered, hybrid life-cycle methodology for city-scale greenhouse gas inventories. Environmental Science \& Technology 42(17): 6455-6461.

[24] Ravindranath, N., Ostwald, M. (2008): Carbon Inventory Methods: Handbook for Greenhouse Gas Inventory, Carbon Mitigation and Roundwood Production Projects. Springer, Netherlands.

[25] Shi, P., Wu, P., Feng, L., Zheng, B. (2010): Study on the design of emission reduction policy framework in China's tourism industry and strategic measures. - Tourism Tribune 25(6): 13-18.

[26] Wang, Q., Yang, X. (2012): Overseas study review of carbon emissions for tourism industry. - Tourism Tribune 1: 73-82.

[27] Wiedmann, T. (2009): A review of recent multi-region input-output models used for consumption-based emission and resource accounting. - Ecological Economics 69(2): 211-222.

[28] Zhang, J., Zhang, J. (2006): Research progress and model modification of ecological footprint. - Resource Science 28(6): 196-203.

[29] Zhang, J., Zhang, J., Liang, Y., Li, N., Liu, Z. (2005): An analysis of touristic ecological footprint and eco compensation of Jiuzhai Valley in 2002. - Journal of Natural Resource 20(5).

[30] Zhang, X., Zhu, Z. (2007): An analysis of tourism environment capacity in Jiuzhai Valley scenic area. - Tourism Tribune 22(9): 50-57.

[31] Zhang, X., Ren, P., Deng, G. (2009): A Study on the strategic management of the sustainable development of Jiuzhai Valley. - Journal of Southwest University for Nationalities (Humanities and Social Sciences Edition) 6: 213-216.

[32] Zhou, X. (1998): Influence of geological environmental deterioration on Jiuzhai Valley ravine landscape. - Carsologica Sinica 17(3): 301-310. 